\title{
A Cidade não Governada Motivações Públicas e Governação Urbana
}

João Seixas *

\begin{abstract}
$\mathrm{R}$ esumo: Perante difíceis e difusas percepções da grande cidade, nos mais variados sectores da sociedade, tem-se tornado cada vez mais complexo exercício de uma gestão e regulação sustentáveis destes territórios urbanos. Porém, não se tem assistido na prática a grandes alterações nos sistemas político, institucional e administrativo. A "cidade real" prossegue o seu caminho de afastamento da "cidade legal". As mais recentes linhas de pensamento ao nível das políticas urbanas apontam-nos interessantes caminhos no sentido de uma governação urbana mais plural, eficiente e visionária, reconhecendo que é também na diversidade que a criatividade e as dinâmicas se desenvolvem. Se as instituições do Estado, nos seus diferentes níveis devem ter um papel charneira de catalisador de uma motivação cultural nesse sentido, os actuais enquadramentos executivo, político e normativo parecem ainda não perspectivar grandes entusiasmos. Mas perante as urgências de actuação, tensões e expectativas suceder-se-ão no cenário urbano de múltiplos actores e influências. Por conseguinte, competirá muito aos movimentos cívicos esse papel de consciencialização, por pressão política, de muitas dimensões "não visíveis" na cidade. Também aqui o reforço da identidade e das representações urbanas é essencial. É pela vertente cultural que se poderá preencher a "terra de ninguém" entre a imobilidade institucional e a desresponsabilidade social.
\end{abstract}

Palavras-chave: Cidade, Governação Urbana, Planeamento Urbano, Organização do Estado, Políticas Urbanas, Movimentos Cívicos.

"La ciudad es la mejor oportunidad de innovación política" Jordi Borja

\section{Percepções da cidade - Que escalas possíveis?}

Reflectimos aqui sobre a gestão da cidade. Sobre o seu governo, suas instituições, sobre os poderes existentes, as influências - e as não influências. Sobre a cidadania. As responsabilidades políticas, as possibilidades e formas de intervenção. Amplamente comentadas e também estudadas, das universidades aos cafés, dos gabinetes ministeriais aos municipais, de que forma se encontram efectivamente percepcio- nadas estas dimensões de intervenção, estas visões de influência? Está a grande cidade actual efectivamente a evoluir de uma forma não governada? E sob que formas se materializa uma governação que se pretenda plural, sustentável, mas também efectiva e eficiente?

No exercício de pensar sobre as dinâmicas, os processos, as decisões, as raízes e formas sobre como a cidade hoje em dia evolui, se produz e reproduz, não se poderá deixar de começar sem deixar de formular uma simples pergunta inicial: na verdade, o que entendemos hoje por "cidade"?

\footnotetext{
* Departamento de Geografia Humana, Universidade Autónoma de Barcelona. Investigador do CET, Lisboa.
} 
A cidade difusa. A cidade genérica. A cidade ocasional. A cidade e a revolução informacional. A metrópole. Ou melhor (e maior), a "metápole". E a cidade real? Quem, na verdade, assume e sabe o que é hoje a cidade? Existem padrões minimamente claros de como a podemos definir? Que novos conceitos de escalas de entendimento deveríamos deter?

Desde o cidadão comum até aos mais eminentes especialistas em questões urbanas, passando pelos decisores e influenciadores mais directos, o pulsar das percepções e das identidades de espaços urbanos, plenos de descontinuidade e de uma difusão de centralidades, são tudo menos pacíficas. Territórios plenos de lugares estética e funcionalmente genéricos, até nas suas dinâmicas comuns (lembrando aqui a excelente estética interpretativa da obra dos arquitectos Koolhaas e Mau, 1995) espalhados por vastos territórios de convivência, sim, de mobilidades múltiplas, sim, mas onde, por essa via, mas também muito pela via da revolução informacional, "o tempo aniquilou o espaço" (Harvey, 1989) ${ }^{1}$, e onde, entre múltiplos outros paradoxos, temos junto a alguns lugares-postal, "não-lugares" que se multiplicam ferozmente, se tornam socialmente explosivos, e que muito amedrontam.

Ao longo dos últimos anos, tem evoluído, de certa forma, um despertar de uma consciência social e cultural, perante a relevância de algumas dimensões de raiz urbana. Não que as questões das cidades não fossem objecto de reflexão, discussão e decisão desde há séculos. Mas vivemos tempos bem mais complexos. Embora, evidentemente, este entendimento social esteja a ser formado muito gradualmente, as grandes mudanças, as condicionantes, causas, consequências, e respectivas urgências da cidade, têm-se instalado de uma forma progressiva nas representações e nos discursos. Uma consciência da grande relevância das questões urbanas para o desenvolvimento e a sustentabilidade actual e futura. Mesmo que, as mais das vezes, essa consciência se manifeste sob formas enviesadas. E mesmo que se esteja, claramente (e infelizmente), ainda muito longe de se entender o verdadeiro alcance de muitas destas questões. As consequências das actuais formas de mobilidade, do uso do solo, da dispersão das densidades, em termos de cruciais valores de sustentabilidade e de futuro começam a ser reconhecidas. Mas, seguramente, ainda muito pouco enquadradas numa estratégia política de actuação pública, cívica, e mesmo privada ${ }^{2}$.

A cidade continua a evoluir, a crescer de uma forma claramente insustentável. Mas porquê, se, pelo menos nalguns aspectos, em algumas consequências, esta insustentabilidade se tem tornado cada vez mais clara e urgente perante todos?

Colocam-se aqui duas grandes linhas de reflexão, e de importante actuação. Por um lado, há a necessidade de se aprofundar o entendimento, a percepção cultural das grandes influências que as "questões urbanas" têm no desenvolvimento sustentável e na qualidade de vida. Tanto ao nível local como global. Tanto para o cidadão comum como para o mais alto responsável ministerial. Muitas destas percepções das consequências da evolução e modos de vida urbanos, apesar de muito fortes, são extremamente intangíveis, difíceis mesmo de quantificar e relacionar.

Por outro lado, e de certa forma decorrente da primeira e prioritária linha, decorre a inevitável necessidade de evolução dos enquadramentos institucionais, políticos e administrativos, e de como estas questões deveriam ser melhor entendidas, geridas e tratadas.

Pode-se dizer que existe hoje, em alguns sectores, uma consciência de que as próprias mudanças urbanas estão sem dúvida a pôr em causa uma grande parte dos paradigmas político-institucionais e estruturas sob as quais se tem regido e fundamentado a ideologia e a actuação da nossa sociedade perante a Polis, confluência de fluxos de sinergia e de ruptura, fundamento da cidadania e da democracia. Mudanças que obrigam a novas atitudes e a uma diferente cultura política na gestão do território. Uma busca de novas formas de estrutura, de organização interna e institucional, de interligação dos poderes locais, de novos enquadramentos de responsabilidade e de responsabilização, de mecanismos de identidade colectiva.

Contudo, não se tem assistido na prática a substanciais alterações nos sistemas de gestão e actuação política e num maior exercício de cidadania. Na verdade, a "cidade real" prossegue o seu caminho de contínuo afastamento da "cidade

\footnotetext{
${ }^{1}$ Nesta área de pensamento sobre a influência das tecnologias de informação no território, existe hoje já uma vastíssima bibliografia. Sugere-se, todavia, o excelente livro de Mitchell (1999), extremamente actual e muito vivo, incidindo este nas influência próximas e quotidianas das mais recentes tecnologias nos modos de viver e sentir a cidade.

${ }^{2} \mathrm{Na}$ interligação entre a difusão da cidade e sua estrutura, e a crescente inadaptação institucional e administrativa, veja-se a excelente edição de Monclús (1996), do Centro de Cultura Contemporània de Barcelona.
} 
legal". E mais ainda da "cidade política". É na verdade esta "cidade política" que actualmente faz o enquadramento da governação. Incluindo, evidentemente, as forças que, consolidadas como lobbies, influem nos processos e nas decisões políticas. Mas a consolidação dos distintos círculos de influência e de poder dificilmente se interliga com a essência da razão de ser governativa. Nas múltiplas formas e atitudes de como e com quem a cidade deveria ser pensada e gerida. Mesmo quando se deve fomentar (especialmente a um nível muito local, mas não necessariamente apenas a esses níveis) um certo sentido, e mesmo dever, de responsabilização e gestão por parte dos cidadãos. A estratégia, a regulação, a avaliação pública, nomeadamente, não se podem desligar destes processos, com o risco de uma apropriação menos pluralista e mais ligada a interesses particulares.

$\mathrm{Na}$ verdade, as visões, as lógicas de actuação são muito distintas nos diferentes sectores coexistentes na cidade. A devida atenção à larga maioria destas "urgências urbanas" implica uma considerável dose de cedências, de partilha, de descentralização e de reorganização de responsabilidades e de poder. Não somente ao nível dos poderes institucionais, mas também perante os direitos e deveres cívicos. Mas a evolução de uma cultura social de fraca propensão para a mudança e mobilização (ainda profundamente presentes na sociedade portuguesa, como bem demonstra Cabral, 1997) não será fácil, quando aliada a um enquadramento muito próprio de redes, canais e interdependências de poder político relacional muito discricionários e pouco plurais (Sousa Santos, 1994, Rosa Pires, 1994 e Ruivo, 2000), práticas essas à muito estabelecidas e enraizadas na nossa cultura.

Perante significativas dificuldades político-institucionais e administrativas, parecerá que a construção de uma cultura de mudança significará, antes de tudo, o desenvolvimento de uma mais clara consciência e percepção cultural das questões urbanas e dos direitos e deveres de cada cidadão. Apesar do carácter urgente em muitas áreas de actuação, este desenvolvimento implica inevitavelmente um longo processo de aprendizagem e a construção de uma estrutura de formação cívica. Concomitantemente, deve levar a uma consequente mobilização sociopolítica, onde o protagonismo, a perseverança e o compromisso terão que ser necessariamente muito fortes. $\mathrm{Ou}$, na ausência de tais processos de mudança, a cidade não governada tornar-se-á cada vez mais num enorme corpo efectivamente ingovernável.

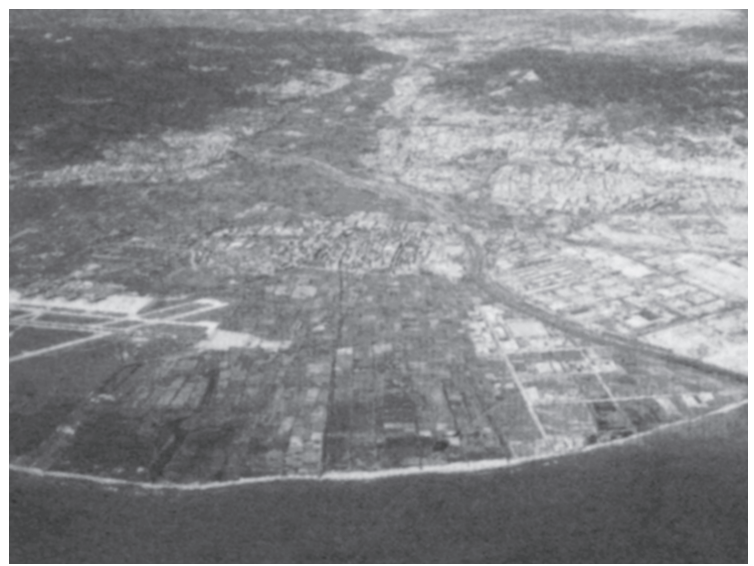

Fonte: Espaço público e interdisciplinaridade, Centro Português de Design.

\section{Políticas da cidade - A evolução nas ideias}

Valerá a pena, neste ponto, efectuar uma breve análise das mais recentes ideias ao nível do pensamento em termos de políticas urbanas e gestão de cidade. Esta recente evolução, uma concreta e urgente busca de novos paradigmas, interliga-se directamente com as fortes transformações que têm ocorrido em dois campos: em primeiro lugar, a manifesta crise nas formas de governo e nos sistemas político e institucional actuais em geral; por outro lado, nas profundas modificações aos níveis social, económico e físico que as áreas urbanas têm sofrido.

A conjugação destas fortes alterações tem criado crescentes tensões, afectando directamente a legitimidade e eficiência das políticas públicas, e dos processos de tomada de decisão. Estas tensões têm grandes implicações nas estratégias, nas capacidades, nas acções e programas afectos ao nível espacial, dimensão encarada cada vez mais como um grande campo de experimentação sociopolítica, reflexões estas muito realçadas por pensadores como Lefebvre (1986), Sousa Santos (1998), Borja (1998), ou Castells (com a sua já famosa trilogia, de 1996 a 1998).

Os próprios Borja e Castells (1997) traduziram de uma forma bastante concreta, incluindo múltiplos exemplos, as emergentes ideias e caminhos por onde a "gestão da cidade na era informacional" estará a encaminhar-se ${ }^{3}$. De uma

\footnotetext{
${ }^{3}$ Livro baseado num detalhado relatório elaborado aquando da conferência Habitat, em Istambul, Junho de 1996.
} 
forma sintetizada, poder-se-ão enunciar os grandes e emergentes vectores por onde o pensamento (e algumas práticas) à volta das políticas urbanas tem evoluído:

a. Na necessidade de uma visão mais multisectorial, implicando o grande desafio da integração de distintos órgãos e fileiras de responsabilidade (e no fundo, de poder);

b. Numa nova e vigorosa necessidade na reorientação do planeamento estratégico (veja-se, nesta área, o excelente livro de Esteve, 1999);

c. Numa mais descentralizada estrutura política e administrativa;

d. Numa clara tendência para a fragmentação, multiplicação e difusão das forças influentes na evolução urbana, acentuando-se ao mesmo tempo alguma concentração de poder em intervenientes particulares, com interesses muito específicos;

e. Numa muito menor rigidez ao nível da elaboração, entendimento e utilização dos planos territoriais, o que implica uma visão com maior flexibilidade e pragmatismo, designadamente em termos de diálogo e negociação (Gaudin e Novarina, 1997). Tal passagem de uma estrutura rígida para uma estrutura bem mais flexível de planeamento implica uma necessidade de grande atenção aos diferentes poderes processuais, e a formas mais substantivas de avaliação e controlo (questões bem explanadas por Healey, 1992, Healey / Williams, 1993);

f. Numa atitude mais "empresarial" (Healey, 1992, Stoker e Young, 1993) por parte das autoridades locais, permitindo não somente políticas mais pró-activas, mas também, o que é fundamental, uma reorganização estrutural interna das instituições;

g. Numa maior interligação entre políticas de providência e apoio social, e políticas de desenvolvimento;

h. Num crescendo gradual de percepção e entendimento, por parte dos variados actores urbanos, na necessidade de uma intervenção mais empenhada, implicando por parte das próprias autoridades públicas, uma busca e formação no sentido de uma maior participação e de valores mais pluralistas nos processos de decisão.

As políticas urbanas e o planeamento urbano tenderão, por conseguinte, para a busca de maiores consensos, para climas de diálogo muitas vezes perante recorrentes objectivos conflitantes e competitivos, rejeitando cada vez mais anteriores abordagens que ignoravam a diversidade e o conflito. Como Santos Silva refere (1997), nenhum consenso é atingido através da dissolução instantânea dos conflitos e das diferenças. Os mais poderosos consensos atingem-se, muitas vezes, através das "tensões produtivas" geradas na interligação das diferentes partes.

Torna-se assim bastante pertinente a introdução do conceito de Governação Urbana, essencialmente desenvolvido por Dunleavy (1980), mas que já vinha sendo explorado por diversos autores de raiz anglo-saxónica (embora alguns autores francófonos também já explorassem essa vertente, muito por via da escola da "sociologia das organizações"). Este conceito de governação urbana reconhece uma crescente tendência para a fragmentação e difusão do poder territorial, e coloca assim a ênfase na necessidade de uma intervenção e visão estratégica plural, através da coordenação dos diferentes actores urbanos, e nos consequentes processos de regulação e legitimação, e nas dinâmicas de negociação (LeGalès, 1995, Bagnasco e LeGalès, 2000). Esta mudança de governo para governação obriga as autoridades territoriais a uma maior estratégia e visão, a serem menos rotineiros e burocráticos, a procurarem ser mais sensíveis perante o ambiente social que os envolve.

Neste sentido, e numa outra sistematização, colocar-se-iam assim os principais desafios que se apresentam aos diferentes órgãos de governo do território urbano, em quatro dimensões primordiais:

1. Uma cultura política de reflexão e tomada de decisões mais descentralizada;

2. Mas, ao mesmo tempo, a busca de uma estrutura de desenvolvimento de uma visão estratégica ao nível da "grande cidade". Uma visão estratégica que inclua a gestão da própria mudança, e distintos conceitos de escalas de intervenção;

3. A evolução para uma nova cultura sociopolítica e administrativa ao nível dos órgãos locais. Uma cultura organizacional mais pró-activa e o desenvolvimento de mecanismos de cooperação, de interligação e de subsidariedade entre os diferentes actores públicos. Uma dinâmica de negociação e de gestão/regulação de diferentes interesses, aberta a procedimentos mais flexíveis. Uma maior preocupação com a formação contínua e actualizada; 
4. Perante uma decisiva e fundamental movimentação cívica da sociedade civil, há a necessidade de uma adaptação dos processos, e mesmo da criação de novos mecanismos e intrumentos no sentido do desejado maior pluralismo e auscultação dos diferentes actores urbanos nos processos de reflexão e tomada de decisão política.

Estas considerações fazem surgir o que aparenta ser um paradoxo extremamente relevante (aliás, vivemos claramente uma época de paradoxos): como combinar a necessidade de um maior pragmatismo, eficiência e flexibilidade nos processos de reflexão e decisão, com a igual necessidade de uma conduta mais estratégica e integrada, com a preocupação num maior pluralismo e em valores de auscultação, e também com as crescentes necessidades de maior justiça, equidade, acção social e distributiva, nestes tempos de crescente polarização social. Ou seja, gerir uma fragmentação que tendencialmente anula as capacidades de planeamento e permite o desenvolvimento de interesses e poderes particulares que não buscam propriamente a sustentabilidade, e procurar integrar uma urgente estratégia precisamente de gestão da sustentabilidade social, morfológica, ambiental, económica.

Estas abordagens de governação urbana, ligadas, em certo sentido, a uma escola (esta sim, bem mais francófona) de regulação, realçam não só o significado dos valores de uma sociedade que se pretende plural em termos das decisões do seu próprio rumo, mas também a grande relevância de uma cuidada e forte gestão pública, precisamente no sentido destes novos processos e formas de actuação (aspecto fortemente realçado nas excelentes reflexões de Ordovás, 2000). Será importante recordar reflexões como as de Harding (1996), quando refere que, na Europa, por existir um acento superior numa "política de consumo", em relação a uma "política de produção" (mais ligada à cultura anglo-saxónica), e por as instituições do Estado ainda deterem, apesar da contínua vaga neoliberal de esvaziamento das funções públicas, um papel relevante em termos de propriedade e desenvolvimento, estas devem assumir-se claramente num papel de charneira.

O enquadramento de governação, ao procurar uma pluralidade nos processos, presume uma forma de gerir o território mais negociada. Neste enquadramento, as autoridades locais detêm o papel de orquestrador, construindo processos catalisadores de cooperação e de inovação (Mayer, 1995). Este "papel catalisador" na construção de novas capacidades processuais prende-se também, e fortemente, com o actual e exponencial desenvolvimento de redes de comunicação, estas próprias modificando profundamente as percepções e actuações territoriais (Esser e Hirsch, 1994).

Ora, em tempos de crise normativa do Estado, e de grandes dificuldades na regulação orçamental, este é um enorme desafio. Mas os caminhos da governação não podem deixar de passar por aqui. Como Healey escreveu (1997:200): "(...)the formal institutions of government have a role in providing a hard infrastructure of a structure of challenges, to constrain and modify dominant centres of power, and a soft infrastructure of relation-building through which sufficient consensus building and mutual learning can occur to develop social, intellectual and political capital".

Se, num território urbano, as instituições públicas formais que temos estarão preparadas para estes desafios, ou se têm capacidade para se adaptar e de desenvolver um humus cultural e sinergético nesse sentido, essa será muito certamente uma das grandes questões a colocar.

$\mathrm{E}$, se, como vimos, a fragmentação urbana a que assistimos hoje é um muito elevado desafio perante a construção de uma estrutura de governação territorial urbana, existe uma outra dimensão que não é menos relevante em termos das dificuldades a enfrentar: os status de poder estabelecidos nos actuais enquadramentos, naturalmente reagem a algum tipo ou tendência de mudança. Privilégios, pequenos e grandes, alguns estabelecidos há longa data, que passam mesmo por modificações políticas de fundo, posicionamentos de lobbies, formas de influência colateral, provavelmente só consentirão a mudança quando esta não se traduzir por uma perda da sua influência.

$\mathrm{Na}$ prática, a evolução a que se tem assistido nos novos tipo de agenda para as autoridades locais, tem sido muito mais no sentido de desenvolvimento de novas formas e esforços de consolidação de uma maior competitividade, de preocupações com crescimento económico, direccionados sobretudo por via de grandes transformações e mesmo eventos. Por esta via também se têm modificado, de alguma forma, os processos de tomada de decisão. Estas pressões de competitividade, apesar do tão propagado fim da era de ouro do neoliberalismo, continuam e acentuam-se. Assim, uma questão crucial será a de comprovar se estas tendências estão a originar resultados menos distributivos e sustentáveis. Se- 
guindo semelhante raciocínio, Wolman e Goldsmith (1992:224) referem que, infelizmente, há muito mais (ou quase somente) discussão em torno "das formas mais eficientes como cada problema ou serviço pode ser resolvido, em vez de se questionarem os novos valores do governo local como instituição política e democrática".

O acesso aos processos de decisão pelas diferentes partes é manifestamente desigual. Não nos iludamos que não o seja de outra forma, evidentemente. Recordar-se-ia Dunleavy (1980) novamente, para lembrar a sua análise das chamadas Comunidades Políticas, ou pequenos círculos onde o poder é administrado e as decisões são tomadas numa forma muito discricionária. Numa conjunção com um Estado em clara crise de valores, uma forma mais fina de "business politics" (Peck, 1995) se desenvolve.

Campos muito significativos de dinâmica sociopolítica influenciarão os resultados na busca de uma distinta "estrutura de conexão". Poderíamos enunciar os que poderão parecer mais significativos:

i) Primeiro, as características globais do território em questão: a riqueza do território, sua distribuição, as distintas situações sociais, o potencial económico, o sistema político, os hábitos processuais e de comunicação em redes;

ii) Segundo, o enquadramento cultural: cidades com uma fraca tradição de empenhamento cívico e participação têm evidentemente muito maiores dificuldades no desenvolvimento de laços de cooperação. Inclusivamente, quando existe uma grande separação entre os sectores público e privado, iniciativas conjuntas serão difíceis e conflituosas, e podem mesmo ser vistas sob a suspeita de favoritismo

iii) As motivações e o poder efectivo das autoridades locais e metropolitanas: lacunas de poder, de recursos, para gerir os processos gera, as mais das vezes, uma situação de dependência perante interesses particulares (privados, partidários,...), que não assumem em primeira linha os fins públicos, e desenvolve hábitos de decisão discricionária; iv) Os graus de interligação e integração nos diferentes níveis governamentais. E evidente que um panorama mais transparente entre as diferentes instituições e órgãos públicos reforçaria a sua legitimidade - o que seria especialmente notório ao nível do poder local;

v) O "tacto político": evidentemente, será virtualmente impossível atingir uma situação de gestão de equilíbrio efectivo com todos os diferentes actores territoriais. Relações de poder assimétricas colocam evidentes diferenças de tratamento na construção cooperativa. O que origina difíceis escolhas e decisões políticas, e muito certamente o risco de novas formas de influência.

Em termos territoriais, poder-se-á afirmar que ao longo dos últimos anos, tem havido, em certo sentido, uma tendência de "reconstrução" das estruturas políticas de governo local. Mas este processo está minado de escolhos. Como bem refere Sousa Santos (1994), encontramo-nos, claramente, numa fase de transição de paradigmas, e no centro de uma clara crise de representação e regulação social, o que tende a provocar situações instáveis, mesmo caóticas. Em tal presente estado, "a promoção da criatividade da acção é uma tarefa crucial" (id. p. 38). Aliás, já Touraine falava desta urgência, de uma "sociologia da acção" (1978). Guerra (2000), no seu mais recente livro, sistematiza de uma forma muito clara os fundamentos e consequentes processos "de uma sociologia de acção". Estará, assim, a cidade preparada para visionar e desenvolver, e mais importante, fomentar e gerir em conjunto esta urgente dinâmica, esta criatividade da acção?

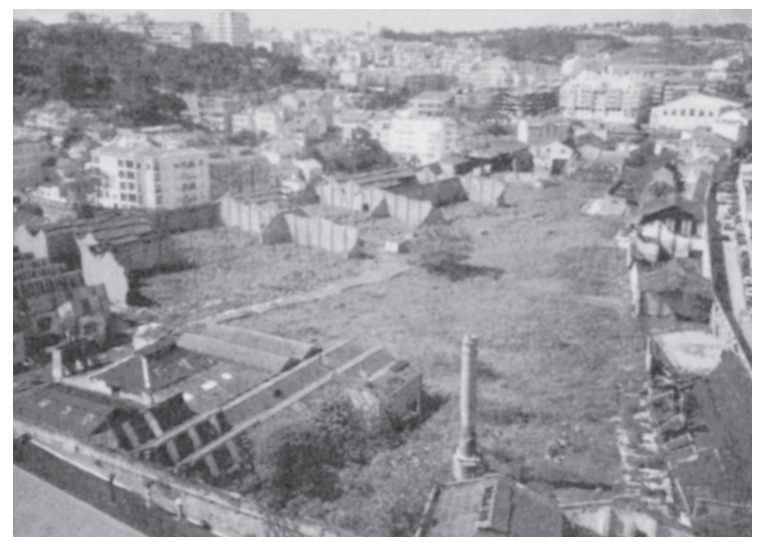

Fonte: Espaço público e interdisciplinaridade, Centro Português de Design.

\footnotetext{
${ }^{4}$ Harding (1996), nas suas análises empíricas, evidencia que em Copenhaga, por exemplo, o envolvimento de privados torna-se extremamente limitado (apesar do controlo público), devido a fortes sentimentos de suspeita de tratamentos desiguais em favor de determinados interesses.
} 


\section{Motivações culturais e sentido cívico perante a cidade}

Quais os sentimentos da sociedade civil portuguesa perante estes urgentes "veículos urbanos de mudança"? Em primeiro lugar, as percepções da cidade. De acordo com um estudo recentemente efectuado (Ferreira, Castro e Casanova, 1999), constata-se que, apesar de uma interessante compreensão perante muitas destas questões, existe, como se esperava, uma elevada componente de "abstracção", uma dificuldade na representação social dos cidadãos face à cidade. Esta difusão de significações, mesmo em termos locais, dificulta a clarificação de representações sociais mais claras e abrangentes, e relevam a propensão dos cidadãos em actuarem, quando muito, em movimentos do tipo NIMBY ${ }^{5}$. Roseta (1999) recorda-nos também como são muito mais difíceis as representações, e o consequente exercício de uma cidadania mais activa, quando estamos em presença de quotidianos muitas vezes "semi-urbanos", em territórios em que "as próprias pessoas nem sabem o que é que lhes falta para virem a ser cidades completas" (p. 182).

No entanto, alguma dinâmica social se tem pressentido. Na última década assistimos a alguns movimentos sociais que desafiaram e paralisaram mesmo algumas decisões políticas entretanto tomadas. Porém, estes movimentos reflectiram-se essencialmente em termos de questões locais muito concretas, e foi decisivo o seu "apadrinhamento" por figuras públicas. Há uma diferença importante entre uma participação social específica e um movimento social de fundo. Não se pode negar, contudo, que é também por estas iniciativas concretas que se fomenta muito de um potencial no sentido da mudança de hábitos estabelecidos, em termos de uma capacidade de intervenção.

Roseta (id.) também concorda que parecem estar a registar-se alguns sintomas de dinamismo cívico em alguns sectores da sociedade portuguesa. E sobre a sua provável especificidade e efemeridade, é importante recordarmo-nos que quando analisamos a evolução de interessantes movimentos de participação cívica em outras cidades, verifica-se que importantes movimentos começaram por acções bem dispersas, de natureza muito localizada e específica. Mas tornaram-se decisivos para o desenvolvimento de uma cultura de cidadania mais participativa, num âmbito mais global. Os dirigentes urbanos dos últimos vinte anos de uma cidade como Barcelona, de certa forma cidade paradigma de uma boa gestão urbana (apesar dos seus problemas próprios, evidentemente), emergiram na sua maioria de associações e movimentos inicialmente localizados. Partiu-se do local para o global (no sentido urbano do termo, bem entendido).

Nesta linha das percepções das questões urbanas, tem também havido uma maior consciencialização das chamadas externalidades na evolução e nas decisões de carácter urbano, mui tas delas, como já referido, verdadeiras "variáveis intangíveis" em termos de sustentabilidade, de ambiente urbano, de qualidade de vida. Estas são dimensões de difícil, mas essencial identificação com as decisões e actuações dos diferentes actores da cidade. Mas, neste campo, o caminho ainda mal começou. Se, por exemplo, ao nível ambiental, ou ao nível de alguns produtos de consumo, esta consciencialização vai ganhando algum peso, assim como alguma materialização dos custos (mas também benefícios) nas decisões tomadas, ainda estamos muito longe de reconhecer que, por exemplo, a utilização massiva de transporte individual na cidade bem poderá provocar custos superiores a $15 \%$ de todo o PIB nacional ${ }^{6}$.

Perante manifestas dificuldades (ou mesmo afastamento, em algumas situações) apontadas ao desenvolvimento de uma nova cultura por parte das instituições públicas, há que realçar definitivamente, e de uma forma bem clara, a necessidade do desenvolvimento de uma estrutura de movimentos cívicos críticos, fora das lógicas, das dependências e dos vícios públicos e municipais, oferecendo aos diferentes actores uma maior confiança para a participação.

Claramente, apesar de existir ainda uma clara distinção entre "simpatia" e compreensão, e a tomada de acções concretas de apoio e participação, alguns resultados de estudos efectuados

\footnotetext{
5 'Not in my Backyard', sigla inglesa muito reconhecida, que transmite os sentimentos dos movimentos locais de reivindicações muito espacialmente específicas e egoístas.

${ }^{6}$ Como recentemente ficou demonstrado através de interessantes estudos efectuados em alguns países Europeus e nos E.U.A., por alguns dos mais reputados especialistas nestas matérias (veja-se, por exemplo, Diputaciò de Barcelona, Àrea de Medi Ambient Disseny d'elements de moderació de la circulació. Aportació a una mobilitat sostenible, 1998). Os custos 'intangíveis' (e portanto de cálculo naturalmente sujeito a discussão e diferentes interpretações) incluíam as perdas de tempo por congestão de tráfico, utilização de solo urbano, externalidades sociais, os custos nas rendas das famílias do usufruto do automóvel, o consumo de combustíveis não renováveis, as emissões na atmosfera, e os acidentes rodoviários.
} 
parecem revelar um crescendo de preocupação com as problemáticas urbanas, nomeadamente na população mais jovem e instruída.

Neste sentido, está implícita uma interiorização dos valores de cidadania, da cooperação e entendimento entre cada um, da busca individual e contributiva para uma melhor qualidade de vida urbana. Mas mesmo nesta dimensão (e muito especialmente nesta dimensão) os poderes de governação podem e devem actuar, num sentido essencialmente formativo (de incentivo a uma maior identidade local), e mesmo de responsabilização.

O papel essencial da "identidade" da clarificação da representação social dos espaços urbanos seus quotidianos, por parte dos cidadãos, é uma dimensão chave nesta motivação cultural. Borja (1998) e Ordovás (2000), muito concretamente, referem a grande importância dos "espaços públicos de formação cívica" e da sua profunda ligação com o exercício activo da cidadania. No seu mais recente texto, Ferreira (2000) desenvolve e contextualiza a profunda relação entre os valores de uma cidadania urbana e os espaços públicos, ambientais e patrimoniais. São estes valores, estes espaços, vectores de relação, de identificação local, acessíveis, abertos, multisociais e multifuncionais, que pressupõem uma apropriação e facilitação do uso social cívico. $\mathrm{E}$, como referem estes autores, trata-se de realçar a importância destes vectores, destes "espaços", como espaços políticos. Um sentimento "de pertença", de consciência dos direitos e deveres da cidadania.

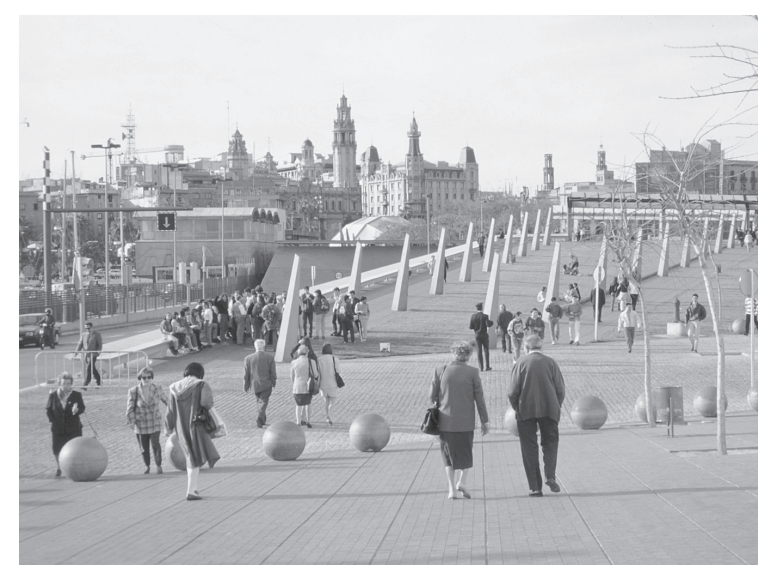

Realçando estas questões, como se tem vindo a verificar cada vez mais, algum deste res- surgir da identidade e na consequente movimentação cívica começa a ser auscultada pelo poder político com uma certa atenção. Para Viegas e Dias (2000), no seu interessante livro sobre os processos actuais de cidadania, integração e globalização, apesar das reconhecidas dificuldades, a reforma das instituições de participação política parece, efectivamente, suscitar um interesse crescente, quer por parte dos meios políticos, quer dos media. Será importante reflectir sobre a forma como a auscultação a estes movimentos seguramente poderão legitimar muito mais o exercício do próprio poder político. Apesar dos riscos de apropriação.

Com efeito, a análise de diversos casos espalhados pelo mundo tem-nos mostrado que, em muitas situações, o desenvolvimento dos mais variados movimentos cívicos urbanos pode acarretar, muitas vezes, ideais muito circunscritos e até pouco plurais (as conhecidas community traps $^{7}$ - veja-se Tam, 1998). Mas, apesar destes evidentes problemas, sem dúvida que num cômputo global o seu fomento demonstra ser altamente compensador, em termos do desenvolvimento de uma cultura de responsabilidade e de maior noção dos deveres sociais da cidadania, de consciencialização e actuação identitária do cidadão com as múltiplas questões de sustentabilidade urbana.

Esta é uma profunda questão cultural. Não falamos aqui somente do sentido do cidadão comum, da rua, e da sua consequente participação em movimentos cívicos. Esta identidade das questões urbanas, esta necessária motivação cultural da sociedade civil, envolve e responsabiliza-nos a todos, incluindo o sector privado, e os próprios agentes no interior das instituições públicas.

Falou-se acima dos níveis das percepções. Como se sabe, são bem distintas as lógicas que movem o sector privado. Não será pouco importante a motivação cultural destes importantes agentes num desenvolvimento sustentado da cidade. Quando se assiste ao desenvolvimento de projectos ainda muito mono-funcionalistas, a uma linha de desenvolvimento socioeconómico que fomenta a separação espacial e social, não se pode deixar de reconhecer a enorme influência destes agentes, e consequentemente a relevância da sua aculturação para estas questões. Como exemplo, e relembrando a questão dos espaços

\footnotetext{
${ }^{7}$ Sobre estas áreas, existe também uma interessante literatura, que analisa questões como os perigos das apropriações e manipulações partidárias, de processos e protagonismos pouco democráticos, ou de reivindicações de carácter egoísta e pouco plural.
} 
públicos, estes, se pensados em termos de uso social colectivo, multifuncional e acessíveis por todos, facilitando as relações sociais, continuarão a ser pouco valorizados numa cultural de exclusiva valorização mercantil do solo. As "variáveis intangíveis" também devem entrar nos cálculos, por muito utópico que tal possa parecer ${ }^{8}$.

Com alguma movimentação da sociedade civil, os líderes e decisores políticos (nos diferentes níveis), e, logicamente, o próprio mercado e sector privado (que, como sempre, será o primeiro a reagir) terão maiores preocupações em assimilar, tentar compreender e muito provavelmente fomentar uma nova cultura de envolvimento, integração e participação que, numa leitura simplista, poderia parecer-lhes contrária ao seu poder. Será um "potencial social" que, a realmente revelar-se, não deixarão de olhar com atenção, de procurar auscultar, e muito provavelmente de coresponsabilizar em estratégias e decisões.

\section{Vontades políticas - A cidade real e a cidade política}

Como vimos, apesar da fundamental relevância de uma motivação cultural cívica, não se pode deixar de reconhecer aos diversos órgãos do Estado um essencial papel de elemento de certa forma dinamizador desta necessária motivação cívica, numa sociedade com grandes dificuldades de afirmação participativa.

Desenvolver diferentes formas de coexistência em espaços mais partilhados implicará não só o desenvolvimento normativo desses espaços, mas sobretudo um trabalho árduo e estrutural de encorajamento e de "instigação" para acções de conexão e esforços comuns entre os diferentes actores territoriais. $\mathrm{O}$ que vai também de encontro às ideias e reflexões mais recentes em termos das urgências e importantes tendências para as políticas urbanas, como vimos. Martins (1998), nos seus ensaios dos anos 60, já excelentemente nos esclarecera como, no nosso país, uma grande estabilidade e homogeneidade social muito ligada a séculos de identificação com um Estado soberano, condiciona em grande medida os "fluxos dissidentes", ou de mudança, no próprio Estado. A situação era outra, é certo, mas na verdade muitas atitudes e posicionamentos não mudaram assim tanto.
Sem dúvida que nestes nossos tempos de democracia mediática, não se pode negar que os líderes e decisores políticos, têm uma muito maior preocupação em entender e assimilar os sentimentos da sociedade civil e das comunidades locais (no caso, urbanas). Apesar de todos os enviesamentos de sentido populista sobejamente conhecidos (cuja análise não é o objecto deste texto) este "potencial social" é olhado e auscultado com cada vez maior atenção. Será sem dúvida também, e talvez essencialmente, por estas vias que muita da pressão no sentido da mudança poderá ser activada.

Assiste-se, apesar de tudo (e acompanhando esse gradual reconhecimento da relevância de algumas questões urbanas) a alguma inclusão nos processos de actuação, de acções de sensibilização social de identificação local, de fomento de instrumentos, processos e espaços de participação, discussão e concertação entre diferentes actores (incluindo entre os diversos departamentos públicos) nos processos de reflexão e tomada de decisões.

Mas muitas dúvidas acompanham inevitavelmente este caminho. Assiste-se, na realidade, a alguma vaga de evolução no sentido da governação participativa? No início da última década, Harding (1990), referia que as novas formas de parceria e de cooperação, e os próprios esforços de organização e desburocratização das instituições, revelavam apenas sinais muito limitados de que as suas "agendas se tivessem alargado", que as suas visões e preocupações fossem outras. De facto, "o mais relevante que se terá atingido terá sido alguma adaptação institucional e de alguns dos seus processos, às dinâmicas económicas" (pág. 122). Apesar das muitas boas intenções, é claro o entendimento de que o desenvolvimento de uma cultura de governação será um longo e muito gradual processo de aprendizagem cultural. Também nesta linha, e recordando o seu conteúdo ideológico, Mackintosh (1992) avisava que "o que se discute hoje ao nível local (...) é uma versão de um mais vasto objecto de conflito sobre o futuro das organizações e o campo de actuação do sector público" (p. 221).

Reflecte-se nestas linhas, essencialmente, percepções por parte das instituições públicas. Percepções de dimensão urbana, metropolitana, mas também extrememente locais. Percepções que implicam estratégia e visão. Sabemos que o

\footnotetext{
${ }^{8}$ Embora, como vimos, variáveis ligadas ao ambiente, nomeadamente, já começam a entrar até mesmo nos cálculos contabilísticos das empresas privadas.
} 
próprio Estado, nos seus diversos ramos, órgãos e departamentos, não deixa de ser um reflexo da sociedade. A "ideia de cidade", a clareza e percepção das questões urbanas por parte dos seus políticos, técnicos e responsáveis espalhados por múltiplos órgãos e departamentos, será muito menos difusa e mais integrada do que a do cidadão comum? Seguramente, esta "clareza de visão" não será muito maior. Assim sendo, tão pouco estará muito evidente nos diferentes níveis do sector público em que sentido dirigir efectivamente as estratégias e acções a empreender.

Será muito relevante, aqui, efectuar algumas reflexões nas áreas por onde certamente se esperarão ver surgir as maiores tensões perante os desafios lançados à cidade não governada. Estas áreas de tensões, ao mesmo tempo, podem ser perfeitamente aquelas onde se situem as mais interessantes e decisivas potencialidades. E, mais uma vez, será importante recordar que se estamos aqui a acentuar a tónica ao nível das instituições do Estado, um papel crucial terá também que ser protagonizado por outros sectores da sociedade, designadamente em termos do papel dos movimentos cívicos.

Temos, em primeiro lugar, um enquadramento executivo. Os diferentes níveis de governo, as suas responsabilidades, os recursos e as interconexões. Se é consensual que, após Abril de 1974, a afirmação do poder local em Portugal tornou-se sem dúvida numa das essenciais áreas de sucesso face aos grandes desígnios nacionais prosseguidos $^{9}$, também se sabe que todo este processo de descentralização política está ainda longe dos seus mais nobres objectivos. Poder-se-á dizer que existem ainda áreas de poder muito centralizadas. Mas existem questões igualmente, ou até mais urgentes, sem as quais não se poderá avançar efectivamente num processo de reforço dos poderes locais.

Um ponto fulcral representa a total desconexão entre a chamada "cidade real" e a "cidade legal". Numa região metropolitana onde, entre outras questões, a enorme difusão dos territórios urbanizados e o incontornável crescimento dos factores de mobilidade e de acessibilidade são manifestos, esta questão é particularmente séria. A difusão e fragmentação de poderes e responsabilidades, sem uma adequada "malha" de intercooperação, não faz mais do que provocar enormes lacunas de efectivo serviço público, um grande desperdício de recursos por actuações não conjuntas, e uma grande dose de competitividade territorial.
Aqui, a tónica deveria ser dada no reforço das responsabilidades, da capacidade de decisão, e dos respectivos recursos, de uma instituição metropolitana. Uma instituição metropolitana o mais possível ligada à "cidade real", com maior poder de coordenação, de influência e de decisão alteraria de uma forma significativa as actuais estratégias e a visão de todo um vasto território urbano. Evidentemente, tal protagonismo implicaria a necessidade de uma outra legitimidade, em princípio a ser sufragada eleitoralmente. Ao mesmo tempo, dever-se-ia apostar numa cultura de reforço na cooperação intermunicipal e entre outros diferentes órgãos de governo. Os diferentes instrumentos e processos de cooperação deveriam ser incentivados fortemente, mesmo a nível fiscal, e num maior apoio programático. Desenvolver-se-ia também por esta via uma cultura de partilha de poderes e de co-responsabilização.

Um outro aspecto essencial prende-se com a actual fragmentação ao nível sectorial. A maioria das instituições com influência em áreas como os transportes, serviços sociais, ou a habitação, entre outras áreas, pouco ou nada têm que ver com o governo local. Pergunta-se como pode existir gestão de cidade com políticas totalmente sectorializadas, sem o mínimo de cooperação e integração de acções?

As reflexões em torno desta questão destacam a importância do papel decisor do Governo Central. O poder de redistribuir competências e responsabilidade em campos como as possíveis novas atribuições a uma instituição metropolitana (que terá a sua legitimidade própria, e consequentemente um inevitável protagonismo político) ou o poder de efectuar fundamentais alterações a áreas do actual enquadramento fiscal e administrativo que pervertem profundamente o sistema, como as actuais fontes de recursos municipais, ou a sempre adiada actualização cadastral dos valores matriciais do edificado urbano, tendo em vista não só uma reforma fiscal mas também alterações em graves situações de inércia, como na lei do arrendamento, que pertence por inteiro aos poderes centrais.

Neste sentido, e em segundo lugar, temos o fundamental enquadramento político. Numa análise aos processos de reflexão e tomada de decisão por parte dos órgãos públicos, nos seus diferentes níveis e esferas, denota-se que o modo como estas entidades interpretam situações, definem objectivos e constroem cooperação,

\footnotetext{
${ }^{9}$ Permitindo, quiçá pela primeira vez de uma forma efectiva, uma importante dose de descentralização política e um novo campo de acção e influência em termos de importantes áreas de responsabilidade e afirmação local.
} 
materializam-se em actuações cuja lógica é, em primeiro lugar, política, e só depois técnica (Santos Silva, 1997). Estas lógicas políticas, reflectidas num sistema partidário que se pressente cada vez mais distante da sua mais nobre função social, afecta as estratégias e decisões prosseguidas com variáveis de influência e balanceamento de poder. Nesta lógica, as "comunidades políticas", que se expressam sob diversas formas e fileiras nas mais variadas áreas de governação, local, regional ou central, detêm um importante controlo em relação às formas de participação, e, por conseguinte, possíveis formas de influência de outros actores em qualquer processo de tomada de decisão. Voltamos às grandes dúvidas sobre novas formas de balanceamento e regulação de poder recentemente analisadas e tentadas.

Ruivo (2000) descreve de uma forma bastante concreta como se processam os actuais e efectivos processos de poder e influência ao nível local em Portugal. Assumindo-se que a "negociação" é, por princípio, uma prática positiva, conotando-se com uma certa pluralidade, partilha e concertação de ideias, já não se poderá pensar o mesmo quando os canais de negociação utilizados são desenvolvidos informalmente por teias e redes de poder relacional. Esta "democracia de acessos" que temos assume uma lógica de decisões fundamentada em esquemas de reciprocidade de influências e de solidariedades partilhadas em círculos muito restritos, que atravessam verticalmente os diferentes níveis do Estado.

Estes processos representam hábitos pouco plurais, acarretando a falta grave de duas dimensões fundamentais em qualquer processo político: primeiro, a não participação de outras entidades, numa cultura de desigualdade de oportunidades, retira a estas (ou não lhes dá) a possibilidade de participação nas reflexões e decisões, não lhes permitindo um importante estímulo e prática de uma cultura de envolvimento e co-responsabilização; depois, através da não participação de outras vozes nos processos, que trariam novas ideias e sugestões às medidas tomadas, estas tornam-se, as mais das vezes, mais pobres de conteúdo e alcance do que efectivamente poderiam proporcionar (Seixas, 2000).
As noções actuais de concertação, segundo Viegas e Dias (2000), materializam-se, frequentemente, apenas ao nível das cúpulas das organizações (um modelo neocorporativista), resultando em políticas legitimadas apenas pelas suas próprias lógicas. Lógicas que não traduzem uma dinâmica de acção construtiva, e que acarretam uma considerável dose de ineficiência para os "fins sociais", perante um Estado ainda poderoso mas ineficiente, e parceiros sociais pouco representativos e com interesses muito particularizados (Sousa Santos, 1994).

Muitos líderes públicos eleitos, sujeitos eles próprios a estas lógicas fracturantes (internas e externas) que lhes dificultam a representação das questões e das vias mais adequadas a empreender, acabam por colocar uma ênfase substancial das suas motivações em projectos de natureza muito específica, bem mais casuística, com uma fraca conexão em termos de uma visão estratégica integrada. Preferem, quase sempre, (ou melhor, pela lógica inapelável do actual sistema, acabam por terem que preferir) agir por meio de projectos individuais, onde o "terreno a desminar" é bem mais perceptível.

Estas formas de gerir um território (deliberadas ou não), aliadas a uma lógica do sistema eleitoral actual, conduzem a um inevitável carácter mais populista do exercício do poder público. $\mathrm{E}$, consequentemente, ao reforço dos canais de relacionamento mais informal, a uma cultura política com menores preocupações estratégicas, e com menor preocupação de auscultação e pluralidade no exercício do poder.

Em terceiro lugar, o enquadramento normativo e administrativo. Muitas das bases dos actuais códigos administrativos provêm ainda do tempo do Estado Novo, com pesados e rígidos regulamentos. Este enquadramento é visto, manifestamente, como um forte adversário processual ao desenvolvimento de uma diferente cultura administrativa. A grande maioria dos responsáveis de departamentos municipais têm referido que o peso do trabalho "processual" é tão elevado e burocrático, que não permite praticamente nenhum tempo de reflexão, de formação, e o necessário desenvolvimento de uma pensada cultura de mudança com vista a uma organização mais pró-activa ${ }^{10}$. Assim foi-se desenvolvendo, ao

\footnotetext{
${ }^{10}$ Para além das também importantes implicações noutros campos: como exemplo, temos que o tempo médio de aprovação de um licenciamento nas grandes cidades portuguesas aproxima-se dos dois anos (percorrendo todas as fases do processo). Sem descurar a importância do controlo e da regulação, há indicações que esta situação encarece a renda habitacional em cerca de $20 \%$. Numa cidade como Barcelona, onde as preocupações com o controlo urbanístico não são menores, o período médio de aprovação (ou de rejeição) tem-se situado em cerca de 5 meses. Ambas as informações foram recolhidas pelos respectivos departamentos camarários de urbanismo e planeamento.
} 
longo de décadas, uma "cultura administrativa" que permite muito pouco espaço para procedimentos, negociações e entendimentos mais flexíveis (como refere Pinho, 1997).

Ao mesmo tempo, esta situação provocou também o desenvolvimento de processos "informais" de contornar as normas vigentes. São inúmeras as situações detectadas onde a "informalidade" ultrapassa efectivamente muitas regras. Independentemente de tornearem obstáculos totalmente inadequados, estas formas de actuação colocam mais uma forte tónica de descrédito no sistema vigente. Ao mesmo tempo, não promove propriamente a cooperação entre diferentes órgãos públicos, pelo menos de uma forma mais institucionalizada. Esta fica dependente das "iniciativas de ruptura" deste ou aquele órgão ou departamento.

De qualquer modo, sem dúvida que é basicamente devido a particulares esforços pessoais ou de determinadas equipas de trabalho, que alguns departamentos municipais e outros órgãos locais têm conseguido desenvolver uma postura pró-activa na sua busca de uma acção interna e externa mais eficiente. Iniciativas deste género demonstram que apesar da rigidez inerente do sistema, é possível o desenvolvimento de uma cultura mais flexível de iniciativa e inovação. Ao mesmo tempo, também abrem possíveis formas e caminhos de mudança do actual enquadramento administrativo do governo público. Como tal, deveriam ser interessadamente analisadas.

Estas considerações recordam-nos quando já nos anos 80, autores como Portas (1989 e 1990) afirmavam a profunda urgência de desenvolvimento de uma visão e cultura (no caso, de planeamento) muito menos rígida, que passasse de defensiva a ofensiva, e que conseguisse orientar os recursos e acções públicas, regulando negociações com os diferentes agentes e minimizando conflitualidades sociais e o consequente desgaste. Estas ideias permanecem profundamente actuais.

Em forma de síntese destas reflexões acerca das tensões e expectativas no seio das instituições, face aos desafios da governação urbana, e relembrando os quatro principais desafios acima enunciados, sugere-se uma sistematização esquemática:

\begin{tabular}{|c|c|c|}
\hline Desafios & Principais Tensões & Principais Expectativas \\
\hline $\begin{array}{l}\text { Uma cultura política de } \\
\text { reflexão e tomada de } \\
\text { decisão mais descentralizada. }\end{array}$ & $\begin{array}{l}\text { - As tendências populistas e personalizadas no } \\
\text { exercício do poder nos municipios. } \\
\text { - Falta de iniciativas fundamentais de nova } \\
\text { legislação por parte do Estado Central, em áreas } \\
\text { chave a desbloquear, como na área fiscal, na área } \\
\text { patrimonial, nos solos e nos órgãos } \\
\text { metropolitanos, entre outras. } \\
\text { - Um sistema administrativo e institucional muito } \\
\text { centralista, com poderes há muito pre-estabelecidos } \\
\text { e comunidades de decisão política fechadas. } \\
\text { - Poderosos lobbies vs. fracos poderes locais } \\
\text { Institucionais, com crescentes responsabilidades. } \\
\text { - Uma grelha de responsabilidades públicas muito } \\
\text { verticalizada, com múltiplas tutelas distintas, e ao } \\
\text { mesmo tempo muito fragmentada, com várias } \\
\text { fronteiras indefinidas. } \\
\text { - Um pesado enquadramento normativo. }\end{array}$ & $\begin{array}{l}\text { - Uma clara crise de tacto político central. } \\
\text { - Um crescente reconhecimento da necessidade de } \\
\text { cooperação entre diferentes organismos. } \\
\text { - Diversos exemplos de sucesso de parcerias e formas } \\
\text { de associativismo e cooperação entre diferentes } \\
\text { organismos públicos. }\end{array}$ \\
\hline $\begin{array}{l}\text { Uma estrutura de desenvolvimento } \\
\text { de uma visão estratégica. }\end{array}$ & $\begin{array}{l}\text { - Falta de instrumentos, meios e incentivos, no } \\
\text { sentido de uma actuação de regulação na gestão } \\
\text { da cidade. } \\
\text { - A rigidez dos actuais Planos, a pesada estrutura } \\
\text { normativa, processual e legislativa. }\end{array}$ & $\begin{array}{l}\text { - O aumento das percepções e representações } \\
\text { sociais dos impactos urbanos, e na urgência } \\
\text { em os considerar nas políticas e estratégias. } \\
\text { - Um certo aumento das noções de subsidariedade } \\
\text { entre diferentes actores. }\end{array}$ \\
\hline
\end{tabular}




\begin{tabular}{|c|c|c|}
\hline \multirow[t]{2}{*}{ Desafios } & Principais Tensões & Principais Expectativas \\
\hline & $\begin{array}{l}\text { - A cultura de competitividade e conflitos entre } \\
\text { os diferentes territórios e sectores sociais. } \\
\text { - Falta de instrumentos de comunicação e de } \\
\text { partilha de informação entre diferentes órgãos. }\end{array}$ & $\begin{array}{l}\text { - A segunda geração de planos. } \\
\text { - Os conselhos municipais. }\end{array}$ \\
\hline $\begin{array}{l}\text { Evolução para uma nova } \\
\text { cultura sociopolítica } \\
\text { e administrativa } \\
\text { nos órgãos locais. }\end{array}$ & $\begin{array}{l}\text { - Forte e estrutural cultura administrativa e } \\
\text { burocrática. } \\
\text { - Forte cultura partidária e elitista, com tendências } \\
\text { populistas no exercício do poder nos municípios. } \\
\text { - Crescente fragmentação de poderes e } \\
\text { responsabilidades, tornando a governação e a } \\
\text { visão estratégica mais difícil. } \\
\text { - Falta de uma clara visão de subsidariedade. } \\
\text { - Relações de poder muitas vezes conflituosas e } \\
\text { competitivas entre diferentes órgãos públicos. } \\
\text { - Dificuldades de conciliar as diferentes dimensões } \\
\text { de escalas de intervenção com a discricionaridade } \\
\text { na transmissão de poderes, e com uma cultura } \\
\text { ainda muito “corporativa", quer em termos de } \\
\text { cada departamento, ou mesmo de diferentes } \\
\text { profissões. }\end{array}$ & $\begin{array}{l}\text { - Os exemplos de aproximação e de consensos } \\
\text { já são relativamente numerosos, e com diferentes } \\
\text { formas e alternativas de cooperação. } \\
\text { - Alguns óptimos exemplos de órgãos e } \\
\text { departamentos públicos muito pró-activos. } \\
\text { - O aumento gradual de exemplos e processos de } \\
\text { negociação, acordos e parcerias. } \\
\text { - Potencialidades criadas por mudanças } \\
\text { organizacionais, visíveis em alguns } \\
\text { departamentos. } \\
\text { - As potencialidades que alguma recente legislação, } \\
\text { potencialmente mais fléxivel, poderá trazer. } \\
\text { - A mudança geracional. } \\
\text { - A actual crise normativa dos poderes instituídos. } \\
\text { - Os conselhos municipais. }\end{array}$ \\
\hline $\begin{array}{l}\text { Adaptação dos processos e } \\
\text { instrumentos para um maior } \\
\text { pluralismo e auscultação } \\
\text { da sociedade civil } \\
\text { e de outros actores da cidade. }\end{array}$ & $\begin{array}{l}\text { - Uma cultura de fraca participação pública. } \\
\text { - Cultura de elites políticas e partidárias muito } \\
\text { fechadas nos processos de poder e de tomada de } \\
\text { decisão. } \\
\text { - Suspeitas estruturais entre os diferentes } \\
\text { sectores/actores da sociedade portuguesa - } \\
\text { culturas muito distintas. } \\
\text { - Falta de uma cultura de "responsabilidade social } \\
\text { e participação" por parte do sector privado. } \\
\text { - Uma fraqueza estrutural nos esforços de } \\
\text { representação cívica e associativismo. }\end{array}$ & $\begin{array}{l}\text { - Um crescente aumento da intervenção e dos } \\
\text { poderes das associações, nomeadamente de } \\
\text { moradores, empresariais e ambientalistas. } \\
\text { - Alguns esforços visíveis de maior cooperação } \\
\text { entre os diferentes actores urbanos, em alguns } \\
\text { exemplos. } \\
\text { - As potencialidades que alguma recente legislação } \\
\text { poderá trazer. }\end{array}$ \\
\hline
\end{tabular}

\section{Perspectivas}

Perante todas estas considerações, que caminhos deverão ser percorridos no sentido de uma maior sustentabilidade na gestão da cidade não governada? Note-se que uma cidade não governada não significa, de forma alguma, uma cidade ingovernável. Para muitos, as actuais metrópoles apresentam-se como territórios praticamente ingovernáveis, dada a sua enorme complexidade, as suas múltiplas dimensões, e muito seguramente a quase insustentável forma de se poder gerir em diferentes escalas, em diferentes dimensões, em diferentes áreas e sectores, com um mínimo de estratégia comum de coordenação e integração de iniciativas.
Há que reconhecer que parte desta gestão urbana não é "governável" (no sentido "estrito" do termo), nem nunca o poderá (nem deverá) ser. Este é um campo que faz parte de um outro intangível, mais profundo e sem dúvida mais pessoal. A cidade também se desenvolve per si, de uma forma, dir-se-ia, quase darwiniana. Assim aconteceu, durante séculos, e não terá sido muito por esta via que as urbes se tornaram mais insustentáveis e com menores valores de qualidade de vida e de ambiente urbano. Não nos podemos esquecer que seria errado, e seguramente pernicioso, não entender que uma parte fundamental da harmonia e sustentabilidade de uma cidade surge desta evolução própria, endógena (se quisermos utilizar um termo mais científico). 
A um nível muito local, de bairro, de rua, esta visão torna-se particularmente importante. Porém, também não nos podemos esquecer que vivemos um outro tempo, as influências são bem mais amplas e os efeitos multiplicadores muito mais ferozes (tanto a nível social como económico). Sociólogos, economistas, e muitos outros, como Sassen ou Krugman, já há muito que nos falam destas poderosíssimas influências, com escalas cada vez maiores. Daí a cada vez maior importância numa estrutura de órgãos e instituições públicas efectivamente inteligente, abrangente, demonstradora.

A profunda diversidade urbana deve ser, precisamente, o elemento basilar de entendimento, de desenvolvimento da crítica, e, consequentemente, de actuação na cidade. Entender essa diversidade, estudá-la, ir abertamente ao seu encontro, direccionar esforços, sentidos e recursos nesse sentido, é seguramente a chave para uma gestão urbana que procura a sustentabilidade na evolução. $\mathrm{O}$ desenvolvimento de uma aculturação cívica e da promoção da criatividade de acção e de participação segue por esta via. Como vimos, o desenvolvimento de sentimentos localistas, se não fundamentados nesta diversidade, podem ter perigosos contornos.

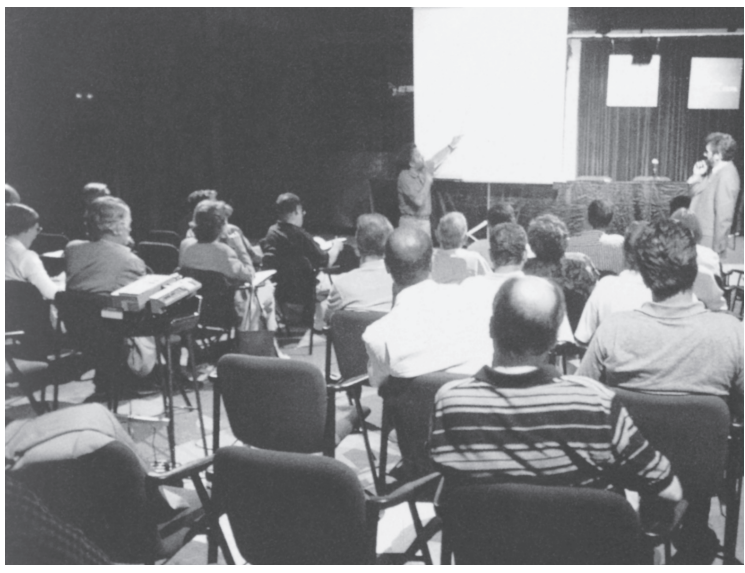

Fonte: Guia per a les actuactions de revitalizacòn en centres histórics i eixos comercials urbans, Generalitat de Catalunya, Dep. d'Industria, Comerç i Turisme

É necessário preencher a actual "terra de ninguém" entre a imobilidade institucional e a desresponsabilidade social. Juntar os actores neste enquadramento cada vez mais difuso e de difícil representação. Apesar das influências de poder e das práticas de discricionaridade política. Evidentemente, não será nada simples. Talvez seja mesmo necessário construir um novo "pacto social" (Sousa Santos, 1998), como, em certo sentido, se iniciou nos finais do século XIX (atendendo à profunda degradação social que a revolução industrial provocava, e que construiu, nomeadamente, o Estado-providência), para se poder governar as novas metápoles. É de realçar que nos mais recentes debates em torno da construção de "uma nova teoria crítica", muitas reflexões se dirigem precisamente para as dimensões espaciais e territoriais.

Parece e deve competir ao Estado um importante papel de catalisador da mudança, de potenciador dos efeitos de multiplicação - e de coordenador da Governação, evidentemente. Uma reforma fiscal, novos quadros normativos de planeamento e negociação, novas gerações de planos, o reforço das autoridades metropolitanas, a correcção das perversões normativas ao nível dos solos, dos valores matriciais, do arrendamento, são todas áreas de fundamental e evidente actuação política. Mas quando se fala do Estado como catalisador da mudança, não é somente em termos destas medidas, mas numa postura de dinamismo e flexibilidade perante a gestão e auscultação da diversidade no território. Porém, como vimos, o Estado encontra-se ele mesmo enredado em múltiplas teias políticas, normativas, competitivas e populistas, ao mesmo tempo que sofre uma profunda crise de valores. Assim, depende muito dos movimentos sociais o potenciar (e mesmo protagonizar) esse papel de catalisador. Catalisando assim o próprio Estado, e as suas instituições (Seixas, 2000).

Evoluções recentes, como a da cidade de Barcelona, mostram-nos como essa transmissão de sinergias e dinâmicas de movimentos cívicos para uma dinâmica institucional (continuando esta, em certo sentido, a ser avaliada socialmente) é possível, e mostra resultados positivos (Nel.lo, 1998, Capel, 1994). Esta cidade passa actualmente por uma certa crise destes valores, mas mesmo assim o que foi criado, mesmo em termos de crítica, consolidou-se o suficiente para agora se recriarem novos movimentos perante novas adversidades. O tão famoso "Modelo Barcelona" não é um plano estratégico. É muito mais que isso. É uma visão integrada, um conjunto sólido de valores, impregnados na sociedade, nos seus cidadãos, nos seus actuantes e decisores nos mais variados sectores (Montaner, 1999). É muito por aqui que se fomenta a governação de uma cidade.

Referindo um outro importante exemplo, temos a cidade brasileira de Porto Alegre, e o seu famoso Orçamento Participativo (veja-se, a este propósito, Genro e Souza, 1998, Abers, 1998, ou Fedozzi, 1997). Uma experiência de gestão e de fiscalidade participada pela sociedade civil já 
com mais de dez anos, e que, consolidando-se a pouco e pouco, tem desenvolvido na cidade um crescente sentido de identidade, e de correspondente participação e mesmo de responsabilização cívica. Num país com uma também difícil propensão para a participação pública. O sucesso desta iniciativa tem-se estendido a outras cidades brasileiras, e já mesmo a Estados (como o próprio Rio Grande do Sul).

Certamente, não pode haver ilusões perante as grandes dificuldades que se levantam. Exige uma forte carga de motivação, um desenvolvimento no sentido da governação urbana, da emancipação de movimentos cívicos críticos, quando na maioria dos casos nos confrontamos com a apropriação dos púlpitos e dos supostos ícones das "posições críticas" por interesses que não se vêm e avaliam, e com uma profunda indefinição e intangibilidade das figuras a percepcionar. Exegir uma crescente percepção das consequências nas decisões, enquanto não se distinguem as diferenças entre mobilidade e acessibilidade, quando não se alteram enquadramentos profundamente graves a nível normativo, quando, simplesmente, não se tem a noção da enorme insustentabilidade social, biofísica e, evidente-

\section{Bibliografia}

ABERs, R. (1998), "La participacion populaire à Porto Alegre au Brésil", Les Annales de la Recherche Urbaine, 80-81.

Bagnasco, A. e Legalès, P. (ed.) (2000), Cities in contemporary Europe Cambridge, Cambridge University Press.

BoRJA, J. (1998), "Ciudadanía y espacio público" in SuBIRós, P. (ed.) "Ciutat real, ciutat ideal - Significat i funció a l'espai urbà modern", Urbanitats $n^{\circ}$ 7. Centro de Cultura Contemporània de Barcelona.

BorJa, J. e Castells, M. (1997), Local \& Global - Management of cities in the information age, Londres Hearthscan Publications.

Cabral, M. Villaverde (1997), Cidadania Política e Equidade Social em Portugal, Oeiras, Celta Editora.

CAPEL, H. (1994), "La transformación de Barcelona en una ciudad bella y bien equipada", Barcelona: La Veu del Carrer, Barcelona, Federación de Vecinos de Barcelona, № 26.

Castells, M. (1996, 1997 e 1998), The information Age: Economy, Society and Culture, Vols. I, II e III, Oxford, Blackwell Publishers.

Dunleavy, P. (1980), Urban Political Analysis, Londres, Macmillan Press. mente, económica, que provoca a dispersão da cidade e a difusão das urbanizações. Para quê tanta pressa na competitividade, se não se equacionam e colocam de uma forma, ao menos, minimamente identificável, as diferentes variáveis da sustentabilidade na mesa?

Assegurar a governabilidade da diversidade. Mesmo, numa observação transversal, a governabilidade por escalas - a por aí, também, a relevância da estratégia. A cidade actualmente não governada exige processos democráticos e participativos, mesmo perante os actuais enquadramentos que nada facilitam este caminho. Mas não se duvide que o futuro da cidade depende profundamente da sua governabilidade. Algumas dimensões de actuação são bem visíveis, como vimos, e a sua aplicação urgente. Novos instrumentos, novos poderes, outros planos e processos são cruciais. Mas, apesar do avanço nestes instrumentos também desenvolver uma alavancagem a uma nova cultura, é necessária a atenção a outras dimensões, mais estruturais, que exigem um apoio, um fermento de compromisso e empenhamento público e cívico. Por estas vias, e muito por pressão, as políticas urbanas actuais tenderão para uma efectiva governação.
Esser, J. e Hirsch, J. (1994), "The crisis of Fordism and the dimensions of a 'Post-Fordist' Regional and Urban structure" in Amin, A. (ed.) Post-Fordism: A reader Blackwell, Oxford.

Esteve, J. (1999), La estrategia de las ciudades, Barcelona, Diputaciò de Barcelona.

FedozZI, L. (1997), Orçamento participativo: reflexões sobre a experiência de Porto Alegre, Porto Alegre, Tomo Editorial.

Ferreira, V. (2000) "Cidade e Democracia. Ambiente, Património e Espaço Público", Cidades, Comunidades e Territórios, 1 , Lisboa, CET/ISCTE.

Ferreira, C. e Casanova (coord.) (1999) Condição social, ambiente urbano e qualidade de vida - OBSERVA Ambiente, Sociedade e Opinião Pública - Observatório do Ambiente Urbano na cidade de Lisboa, Lisboa, ISCTE.

Gaudin, J. e Novarina, G. (1997), Politiques Publiques et Négociation, Paris, CNRS Éditions.

Genro, T. e Souza, U. (1998), Presupuesto participativo - la experiencia de Porto Alegre, Editorial Universitária de Buenos Aires.

Guerra, I. (2000), Fundamentos e processos de uma sociologia de acção - O planeamento em ciências sociais, Cascais, Principia. 
Harding, A. (1990), "Public-Private partner-ships in urban regeneration" in CAMPBELL, M. (ed.) Local economic policy, Londres, Cassell Education.

HaRding, A. (1996), Coalitionformation and Urban redevelopment: A cross-national study, Full summary of a research project funded by the UK Economic and Social Research Council’s Local Governance Programme (1993-1995).

Healey, P. (1992)" The reorganisation of the state and market in planning" in Urban Studies, 29(3).

Healey, P. (1997), Collaborative planning: Shaping places in fragmented societies, Londres, Macmillan.

Healey, P. e Williams, R. (1993), European urban planning systems: diversity and convergence in Urban Studies, $30(4 / 5)$.

HaRley, D. (1989), The condition of postmodernity, London, Blackwell.

LE GalÈs, P. (1995), " Du Gouvernement des villes à la Gouvernance urbaine", Revue Françai-se de Science Politique $10(1)$.

LeVÈBVRe, H. (1986), La production de l'espace, $3^{\mathrm{a}}$ edicão, Paris, Anthropos.

KoolhaAs, R. e Mau, B. (1995), $S, M, L, X L$, Roterdão, 010 Publishers,

Mackintosh, M. (1992), "Issues of policy and negotiation" in Local Economy 7(3).

Martins, H. (1998), Classe, status e poder, Instituto de Ciências Sociais da Universidade de Lisboa.

MaYer, M. (1994), Post-Fordism in city politics in Amin, A. (ed.) Post-Fordism: A reader, Oxford, Blackwell.

Mitchell, W. (1999), e-topia: urban life, Jim - but not as we know it, Cambridge MIT Press, MA.

Monclús, J. (ed.) (1996), La ciudad dispersa, Centro de Cultura Contemporània de Barcelona.

Montaner, J. (1999), Els models Barcelona in Barcelona 1979/2004 - del desenvolupament a la ciutat de qualitat, Ajuntament de Barcelona (ed.).

Nel.Lo, O. (1998)," Reflexions: El futur de Barcelona", Medi Ambienti. Tecnologia i Cultura, 22, Barcelona.

Ordovás, M. (2000), Políticas y estrategias urbanas - La distribución del espacio privado y público en la ciudad, Madrid, Editorial Fundamentos.
PECK, J. (1995), " Moving and Shaking: business élites, state localism and urban privatism" in Progress in Human Geography, 19(1).

Pinho, P. (1997)," Local Planning and National Environmental Assessment procedures: The Developer's Mitigated role in Disjointed Negotiation Processes" in Urban Studies, 34 (12).

Portas, N. (1989), "Os planos para Lisboa", Sociedade e Território $\mathrm{N}^{\mathrm{o}} 10 / 11$.

Portas, N. (1990), "Urbanismo regrado, urbanismo negociado" in Cadernos Municipais, Ano 2 (53), Lisboa.

Rosa Pires, A. (1994), "O planeamento e o desafio da cidadania", in Civitas - A Europa dos cidadãos, Lisboa.

Roseta, H. (1999), "Cidadania activa, movimentos sociais e democracia participativa", Revista Crítica de Ciências Sociais, 54.

Ruivo, F. (2000), O Estado labiríntico, Porto, Edições Afrontamento.

Santos Silva, A. (1997), "Cultura: Das obrigações do Estado à participação", Sociologia - Problemas e Práticas, 23. Centro de Investigação e Estudos de Sociologia, Lisboa, ISCTE.

SEIXAS, J. (2000), "Que inovações possíveis para o Governo Urbano em Lisboa?" Scripta Nova - Revista de Geografía y Ciencias Sociales, Nº9, Universidade de Barcelona

Sousa Santos, B. (1994), Pela Mão de Alice. O social e o político na Pós-Modernidade - $5^{\mathrm{a}}$ edição, Porto, Edições Afrontamento.

Sousa Santos, B. (1998), Reinventar a democracia, Fundação Mário Soares, Lisboa, Gradiva.

Stoker G. E Young, S. (1993), Cities in the 1990's, Harlow, Longman.

Tam, H. (1998), Communitarianism - A new agenda for politics and citizenship Houndmills, Macmillan Press.

Touraine, A. (1978), "Théorie et Practique d'une Sociologie de l'Action", Sociologie et Societés, X (2).

Viegas, J.M. e Dias, E. (org.) (2000), Cidadania, integração e globalização, Oeiras, Celta Editora.

Wolman, H. and GoldSMith, M. (1992), Urban politics and policy: A comparative approach, Oxford, Blackwell. 